JMEMME (Journal of Mechanical Enggineering, Manufactures, Materials and

Energy), Vol. 3 (01) Juni (2019) p-ISSN: 2549-6220e-ISSN: 2549-6239

Doi: 10.31289/imemme.v3i1.2417

JMEMME (Journal of Mechanical Engineering, Manufactures, Materials And Energy)

Available online http://ojs.uma.ac.id/index.php/jmemme

\title{
ANALISIS KEKUATAN STRUKTUR RANGKA MESIN PENGERING BAWANG MENGGUNAKAN PERANGKAT LUNAK ANSYS APDL 15.0
}

\section{ANALYSIS OF FRAME STRENGTH ON ONION DRYER MACHINE WITH ANSYS APDL 15.0 SOFTWARE}

\author{
Azwir Sofyan*, Jean Glusevic, A.J. Zulfikar, Bobby Umroh \\ Program Studi Teknik Mesin, Universitas Medan Area \\ Diterima: 08-04-2019; Disetujui: 24-06-2019; Diterbitkan: 30-06-2019 \\ *Corresponding author: : azwirsofyan097@gmail.com
}

\begin{abstract}
Abstrak
Jenis teknologi untuk memproses bawang merah berdampak pada mutu bawang merah yang dihasilkan. Proses pengeringan bawang merah adalah salah satu faktor penting untuk menghasilkan kualitas terbaik bawang merah. Teknologi yang ramah lingkungan dan mudah dioperasikan merupakan teknologi yang diinginkan. Pada proses perancangan mesin, kekuatan bahan dan struktur merupakan faktor utama dari suatu bangunan mesin. Perhitungan dengan menggunakan metode elemen hingga (MEH) ialah salah satu pilihan untuk mendapatkan informasi distribusi tegangan pada suatu struktur mesin. Tujuan penelitian ini ialah: (1) perhitungan beban pada struktur rak (tray), (2) distribusi tegangan pada struktur tray, dudukan, dan rangka pengering bawang merah, dan (3) analisa kekuatan bahan menggunakan metode Tresca dan Energi Distorsi. Dalam penelitian ini, perhitungan MEH dikerjakan dengan bantuan software Ansys APDL 15.0. Beban input berasal dari berat tray dan bawang yang akan dikeringkan. Metode analisis menggunakan MEH dengan jenis analisa structural dan jenis elemen Beam 3Node 189. Berdasarkan hasil simulasi MEH, tegangan maksimum yang terjadi pada tray ialah 1,22 MPa dan defleksi maksimum ialah 0,0055 mm. Tegangan maksimum pada struktur dudukan tray ialah 33,25 MPa dan defleksi maksimum $0,014 \mathrm{~mm}$. Tegangan maksimum pada struktur rangka mesin pengering bawang ialah 0,89 MPa dan defleksi maksimum $0,000235 \mathrm{~mm}$ yang terjadi pada bagian tengah struktur mesin. Berdasarkan teori Tresca dan Energi Distorsi, diperoleh bahwa tegangan yang terjadi masih jauh dari kriteria kegagalan struktur. Demikian juga dengan defleksi yang terjadi adalah sangat kecil sehingga konstruksi mesin pengering bawang aman dipergunakan.
\end{abstract}

Kata kunci: Pengering Bawang Merah, MEH Simulasi, Analisa Kegagalan

\begin{abstract}
Typical technology for processing red onion affects the quality of red onion produced. The process of drying red onion is one of the important factors in producing the best quality of red onion. Environmentally friendly and easy operation and maintenance technology is the desired technology. In the process of engine design, the strength of the material and structure are the main factors of the building of the machine. Calculation with finite element method (FEM) is the best choice to obtain information on stress distribution on a machine structure. In this study, the calculation of the FEM method was assisted by Ansys APDL 15.0 software. The objectives of this study were: (1) calculation of the load on the tray structure (2) the distribution of stress on the tray structure, seat, and frame for red onion dryers, and (3) analyzing the strength of the material using the Tresca and Energy Distortion methods. The input load comes from the
\end{abstract}


weight of the tray and red onion. The analytical method used is the finite element method with the type of structural analysis and Beam 3Node 189 element type. Based on the FEM simulation results, the maximum stress that occurs in the tray is $1.22 \mathrm{MPa}$ and the maximum deflection is $0.0055 \mathrm{~mm}$. The maximum stress in the tray support structure is $33.25 \mathrm{MPa}$ and the maximum deflection is $0.014 \mathrm{~mm}$. The maximum stress on the frame structure of the onion drying machine is $0.89 \mathrm{MPa}$ and the maximum deflection is 0.000235 $\mathrm{mm}$ which occurs in the middle of the machine structure. Using the Tresca and Distortion Energy theories, it is found that the stresses that occur are still far from the failure criteria for all structures. Likewise, the deflection that occurs is very small so that the construction of the onion drying machine is safe to use.

Keywords: Red Onion Dryer, FEM Simulation, Failure Analysis

How to Cite: Sofyan, A., 2019, Analisis Kekuatan Struktur Rangka Mesin Pengering Bawang Menggunakan Perangkat Lunak Ansys Apdl 15.0, JMEMME (Journal of Mechanical Engineering Manufactures Materials and Energy), 3 (01): 20-28. 


\section{PENDAHULUAN}

Alat pengering bawang system tray/rak adalah sebuah alat yang dibuat untuk mengeringkan bawang dengan kapasistas $5 \mathrm{~kg} /$ proses (Zulfikar, Sofyan, \& Siahaan, 2018). Dalam perancangannya, alat pengering bawang ini belum pernah dilakukan pengujian struktur rangka. Oleh karena itu perlu dilakukan pengujian dengan menggunakan perangkat lunak ANSYS yang mampu menganalisa struktur dari rangka dari alat pengering bawang (Zulfikar, 2018). Dalam merancang suatu struktur perlu ditetapkan prosedur pemilihan material yang sesuai dengan kondisi aplikasinya. Kekuatan atau kekakuan material bukan kriteria satusatunya yang harus dipertimbangkan dalam perancangan struktur, namun kekuatan material sama pentingnya dengan sifat material lainnya seperti kekerasan, ketangguhan, yang merupakan kriteria penetapan pemilihan bahan ( Chen, Chen, \& Lin, 2018). Kekuatan material struktur dapat dihitung dan disimulasikan melalui percobaan uji tarik dengan menggunakan pendekatan numerik (Hidajat \& Lulus, 2005). Hasilnya kemudian dibandingkan dengan kekuatan luluh bahan sehingga diperoleh faktor keamanan bahan.

Dalam bidang rekayasa dan engineering, umumnya digunakan piranti lunak untuk membantu penyelesaian kasus yang telah ditentukan (Kalikate, Patil, \& Sawant, 2018). Salah satu software yang biasa digunakan dalam perancangan adalah ANSYS (Chandra, 2009). Berbagai analisa dapat dikerjakan dengan bantuan software ini, seperti analisa structure (global maupun lokal). Selain itu, software ini dapat juga digunakan untuk analisa: thermal, fluids/CFD, couplefield dan electromagnetic's serta berbagai case engineering lainnya (ANSYS Mechanical APDL Structural Analisis Guide, Release 14.0, 2011).

Tegangan $(\sigma)$ dalam suatu elemen mesin adalah besarnya gaya yang bekerja tiap satuan luas penampang. Tegangan dapat diketahui dengan melakukan pengujian, dan besarnya kekuatan sangat tergantung pada jenis material yang diuji (Shigley, 2006). Rumus untuk mencari nilai tegangan diperlihatkan pada persamaan (1).

$$
\sigma=\frac{F}{A}
$$

$$
\begin{aligned}
\text { Dengan : } \sigma & =\text { Tegangan }\left(\mathrm{N} / \mathrm{m}^{2}\right) \\
\mathrm{F} & =\text { Gaya yang diberikan } \\
& (\mathrm{N}) \\
\mathrm{A} & =\text { Luas Penampang }\left(\mathrm{m}^{2}\right)
\end{aligned}
$$

Regangan $(\varepsilon)$ merupakan laju perubahan ukuran bahan akibat beban yang dialami bahan tersebut (Shigley, 2006). Regangan rata-rata dinyatakan oleh perubahan panjang dibagi dengan panjang awal. Secara matematis, hubungan ini diperlihatkan pada persamaan (2).

$$
\varepsilon=\frac{\Delta L}{L}
$$

Dengan : $\varepsilon=$ Regangan

$$
\begin{aligned}
\Delta \mathrm{L}= & \text { Perubahan Panjang } \\
& \text { Batang }(\mathrm{m}) \\
= & \mathrm{L}_{1}-\mathrm{L} \\
\mathrm{L}_{1}= & \text { Akhir Panjang Batang } \\
& (\mathrm{m})
\end{aligned}
$$




$$
\mathrm{L}=\underset{(\mathrm{m})}{\text { Panjang Awal Batang }}
$$

Hukum Hooke merupakan hubungan antara tegangan dan regangan yang terjadi pada daerah elastis pada suatu bahan akibat beban yang dialami bahan tersebut (Shigley, 2006). Hukum Hooke dapat diterjemahkan menjadi persamaan dimana tegangan berbanding lurus dengan regangan, seperti diperlihatkan pada persamaan (3).

$$
\begin{aligned}
& \sigma=E . \varepsilon \text { atau } E=\frac{\sigma}{\varepsilon} \\
& \text { Dimana : } \sigma=\text { Tegangan } \\
& \mathrm{E}=\text { Modulus Elastisitas } \\
& \varepsilon=\text { Regangan }
\end{aligned}
$$

Teori tegangan geser maksimum memprediksi bahwa kegagalan bahan dimulai ketika tegangan geser yang terjadi melebihi tegangan izin maksimum dari sebuah elemen. Teori tegangan geser maksimum juga disebut sebagai teori Tresca atau teori Guest (Shigley, 2006). Teori ini dirumuskan seperti diperlihatkan pada persamaan (4).

$$
\tau_{\max }=\frac{\sigma_{1}-\sigma_{3}}{2} \geq \frac{S_{y}}{2}
$$

Kegagalan terjadi apabila $\frac{\sigma_{1}-\sigma_{3}}{2}$ lebih besar dari $\frac{S_{y}}{2} . S_{y}$ merupakan yield strength, yakni nilai meluluhnya suatu bahan akibat beban yang diberikan.

Energi distorsi terjadi jika energi regangan distorsi persatuan volume mencapai atau melebihi energi regangan distorsi persatuan volume untuk menghasilkan tegangan dari elemen yang sama. Teori energi distorsi berkaitan dengan teori Von Misess Stress (Shigley, 2006). Teori energi distorsi ini bisa membuktikan apakah hasil tegangan eqivalen simulasi sesuai dengan hasil perhitungan teori energi distorsi. Teori ini dituliskan dalam bentuk persamaan (5).

$$
\begin{aligned}
& \sigma^{\prime} \geq S y \\
& {\left[\frac{\left(\sigma_{1}-\sigma_{2}\right)^{2}+\left(\sigma_{2}-\sigma_{3}\right)^{2}+\left(\sigma_{3}-\sigma_{1}\right)^{2}}{2}\right]^{1 / 2} \geq S y}
\end{aligned}
$$

Kegagalan terjadi apabila
$\left[\frac{\left(\sigma_{1}-\sigma_{2}\right)^{2}+\left(\sigma_{2}-\sigma_{3}\right)^{2}+\left(\sigma_{3}-\sigma_{1}\right)^{2}}{2}\right]^{1 / 2}$ lebih besar dari $S y . S_{y}$ merupakan yield strength, yakni nilai meluluhnya suatu bahan akibat beban yang diberikan.

ANSYS adalah suatu perangkat lunak komputer yang mampu menyelesaikan persoalan persoalan elemen hingga dari pemodelan hingga analisis (Zulfikar, 2018). Ansys ini digunakan untuk mensimulasikan semua disiplin ilmu fisika baik statis maupun dinamis, analisis struktural (keduaduanya linier dan nonliner), perpindahan panas, dinamika fluida, dan elektromagnetik untuk para engineer (Kohnke, 1999). ANSYS dapat mengimpor data CAD dan juga memungkinkan untuk membangun geometri dengan kemampuan yang "preprocessing". Demikian pula dalam preprocessor yang sama, elemen hingga model (jaring alias) yang diperlukan untuk perhitungan dihasilkan. Setelah mendefinisikan beban dan melakukan analisis, hasil dapat dilihat sebagai numerik dan grafis. ANSYS bekerja dengan sistem metode elemen hingga, 
dimana penyelesaiannya pada suatu objek dilakukan dengan pendeskritisasian dimana membagi atau memecah objek analitis satu rangkaian kesatuan ke dalam jumlah terbatas elemen hingga yaitu menjadi bagianbagian yang lebih kecil dan dihubungkan dengan node (Hidajat \& Lulus, 2005).

Hasil yang diperoleh dari ANSYS ini berupa pendekatan dengan menggunakan analisa numerik. Ketelitiannya sangat bergantung pada cara kita memecah model tersebut dan menggabungkannya (Novian \& Rahmawati, 2015). Secara umum, suatu solusi elemen hingga dapat dipecahkan dengan mengikuti 3 tahapan. Tahapan Ini merupakan panduan umum yang dapat digunakan untuk menghitung analisis elemen hingga. Dalam penelitian ini digunakan suatu software bantu yang cukup populer di kalangan engginer yaitu ANSYS APDL 15.0. dimana software program ini mampu melakukan analisa beban, pengaruh temperatur, deformasi, defleksi, tegangan pada truss, dan sebagainya.

Tujuan penelitian ini ialah: (1) analisa beban statik yang terjadi pada rangka alat pengering bawang, (2) analisa numerik beban statik yang terjadi pada rangka alat pengering bawang dengan bantuan software Ansys, dan (3) analisa kekuatan struktur berdasarkan teori kegagalan tegangan geser maksimum dan energi distorsi.

\section{METODOLOG}

Alat yang digunakan dalam penelitian ini ialah: 1 Unit Laptop $H P$ 1EGF192, Software ANSYS APDL 15.0, dan beberapa alat ukur, antara lain: vernier caliper, meteran, dan timbangan digital. Langkah-langkah simulasi dengan menggunakan ANSYS APDL 15.0 adalah sebagai berikut: (1) proses preferensi merupakan langkah pendahuluan untuk menentukan model analisis terhadap kondisi material yang ada, (2) menentukan sifat elemen material (Element type), yaitu menentukan sifat elemen uji yang akan digunakan, (3) menentukan Real Constant adalah untuk mendefenisikan jenis elemen uji, (4) material Propertis adalah menendefenisikan jenis material yang akan digunakan dengan tujuan untuk mengetahui sifat stress dan strain dari material, (5) proses Modeling adalah proses membuat model benda yang akan di uji, (6) meshing adalah proses pembagian model menjadi elemenelemen kecil, (7) displacment adalah menentukan letak titik tumpuan, (8) force adalah Penerapan Load (beban) dengan pemberian gaya yang akan diberikan, (9) solve adalah langkah kerja untuk menghitung semua variable yang telah dimasukkan, (10) general Postproc berfungsi untuk melihat hasil perhitungan dari simulasi dalam berbagai bentuk seperti Countur, Path, dan juga List.

Secara keseluruhan, alur penelitian ini digambarkan dalam bentuk diagram alir yang diperlihatkan pada gambar (1). 


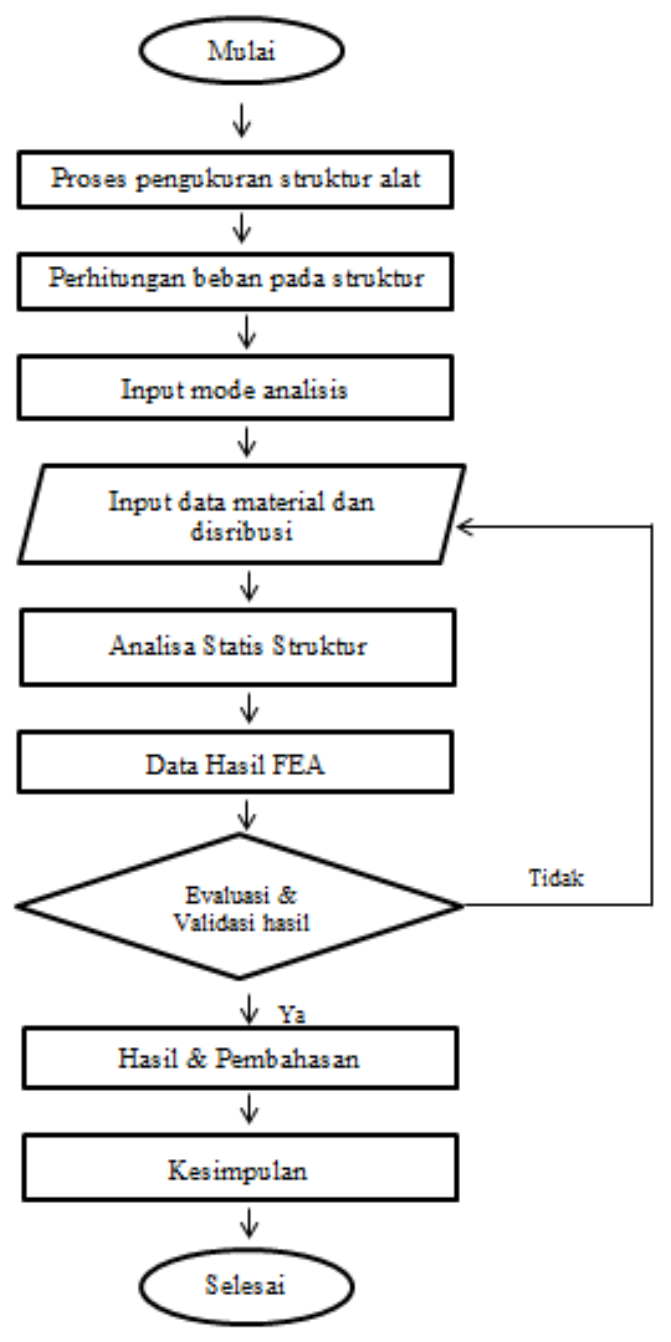

Gambar 1. Diagram alir penelitian

\section{HASIL DAN PEMBAHASAN}

Berdasarkan hasil penelitian, perhitungan pembebanan yang terjadi pada rangka bertujuan untuk mengetahui gaya yang terjadi pada tumpuan yang terdapat pada rangka alat pengering bawang. Dari hasil pengambilan data diketahui bahwa berat Rak $=2,30 \mathrm{~kg}$. Berat bawang yang di muat pada tray/rak pada setiap proses adalah $1 \mathrm{~kg}$.

$$
\begin{aligned}
& \mathrm{W}_{\text {Total }}=\mathrm{W}_{\text {bawang }}+\mathrm{W}_{\text {Rak }} \\
& \mathrm{W}_{\text {Total }}=2,30 \mathrm{~kg}+1 \mathrm{~kg} \\
& \mathrm{~W}_{\text {Total }}=3,40 \mathrm{~kg}
\end{aligned}
$$

Untuk mendapat gaya yang terjadi akibat pembebanan massa, maka massa keseluruhan harus di ubah menjadi satuan gaya.

$$
\begin{aligned}
& F=m \cdot g \\
& F=3,40 \mathrm{~kg} \times 9,8 \mathrm{~m} / \mathrm{s}^{2} \\
& \mathrm{~F}=33,32 \mathrm{~N}
\end{aligned}
$$

Hasil simulasi pada profil L struktur batang tray terhadap perpindahan nodal akibat beban yang diberikan diperlihatkan pada Gambar 2 hasil simulasi. Berdasarkan hasil simulasi, perpindahan maksimum terjadi pada posisi tengah batang dengan perpindahan maksimum $0.055 \mathrm{~mm}$. Perpindahan yang terjadi sangat kecil, sehingga hampir tidak terlihat perubahan bentuk struktur. Besar tegangan yang terjadi pada hasil simulasi adalah sebesar 1.2205 MPa.

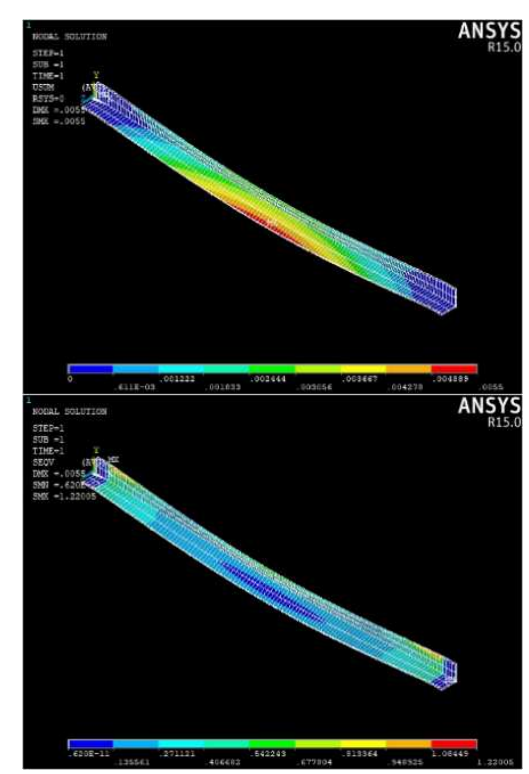

Gambar 2 Hasil simulasi pada profil L struktur batang tray

Hasil simulasi pada penahan dudukan tray terhadap perpindahan 
nodal akibat beban yang diberikan diperlihatkan pada gambar 3 hasil simulasi. Berdasarkan hasil simulasi, perpindahan maksimum terjadi pada posisi tengah batang dengan perpindahan maksimum $0.014029 \mathrm{~mm}$. Perpindahan yang terjadi sangat kecil, sehingga hampir tidak terlihat perubahan bentuk struktur. Berdasarkan hasil simulasi, besar tegangan ekuivalent (Von Misess) maksimum yang terjadi adalah sebesar 33.250 MPa.
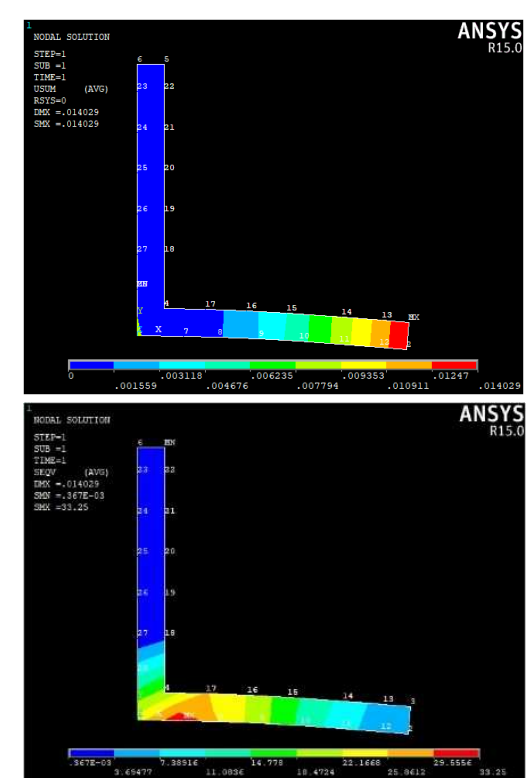

Gambar 3. Hasil simulasi pada penahan dudukan tray

Secara grafis, defleksi pada dudukan dan tegangan Von Misess diperlihatkan pada gambar 4 .

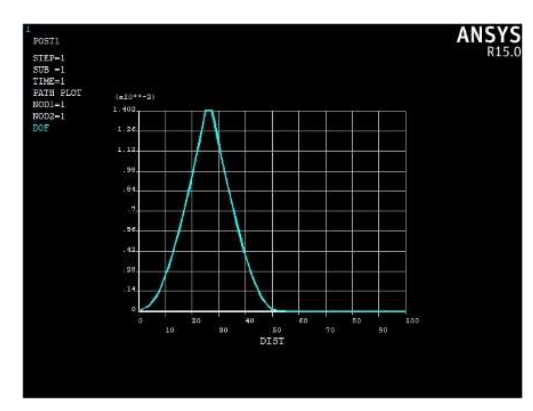

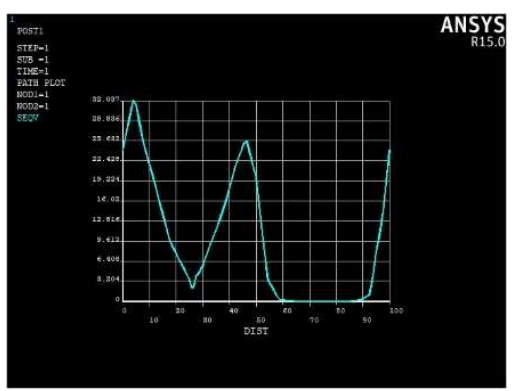

Gambar 4. Grafik defleksi pada dudukan tray dan tegangan Von Misess

Berdasarkan hasil simulasi, perpindahan maksimum terjadi pada posisi tengah batang dengan perpindahan maksimum $0.000235 \mathrm{~mm}$. Perpindahan yang terjadi sangat kecil, sehingga hampir tidak terlihat perubahan bentuk struktur. Berdasarkan hasil simulasi, besar tegangan Von misess maksimum yang terjadi adalah sebesar $0.860552 \mathrm{MPa}$. Secara visual hasil simulasi tersebut diperlihatkan pada gambar 5 .

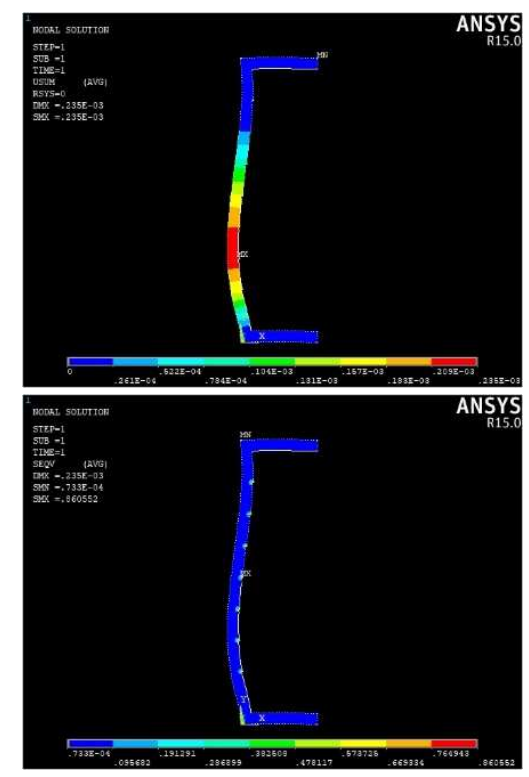

Gambar 5. Hasil simulasi pada struktur rangka

Secara grafis, defleksi pada rangka dan tegangan Von Misess diperlihatkan pada gambar 6 . 

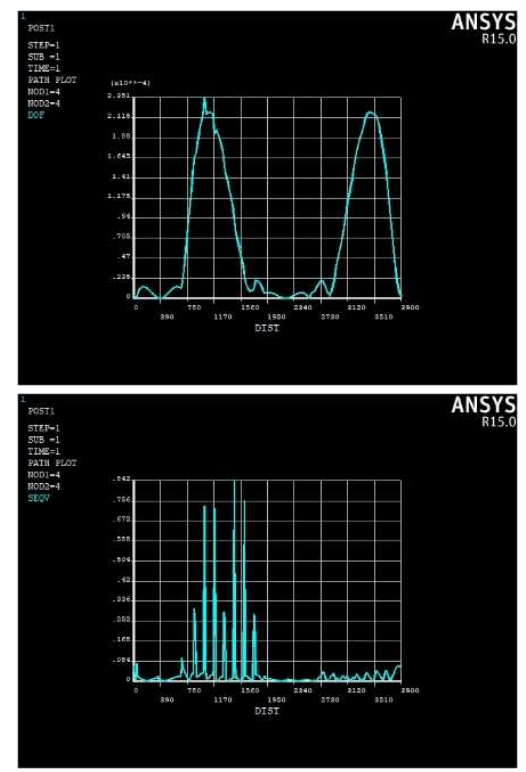

Gambar 6. Grafik defleksi pada dudukan tray dan tegangan Von Misess

\section{KESIMPULAN}

Berdasarkan hasil penelitian, diperoleh kesimpulan sebagai berikut : (1) berat tray ialah 2,32 $\mathrm{kg}$ dan ditambahkan dengan berat bawang $1 \mathrm{~kg}$, sehingga total beratnya ialah $3,32 \mathrm{~kg}$. Selanjutnya berat ini dikonversikan ke satuan gaya, sehingga diperoleh beban tray yang akan digunakan untuk simulasi. Gaya yang terjadi pada tray ialah sebesar 33,32N, (2) Hasil simulasi pembebanan pada tray ialah: defleksi maksimum terjadi pada bagian tengah batang dengan nilai sebesar $0.0055 \mathrm{~mm}$. Berdasarkan hasil simulasi ini menunjukkan bahwa defkelsi yang tejadi pada struktur tray sangat kecil sekali sehingga struktur aman terhadap beban tersebut. Tegangan maksimum yang terjadi pada tray terdapat pada daerah ujung batang. Besarnya tegangan ialah 1,22 MPa. Defleksi maksimum pada dudukan tray yang terjadi pada bagian ujung penampang, yaitu sebesar 0,014029 $\mathrm{mm}$, sedangkan pada rangka utama defleksi maksimum terjadi pada bagian tengah rangka, yaitu sebesar 0,000235 mm. Tegangan maksimum pada dudukan tray terjadi pada bagian bawah dudukan, yaitu sebesar 33,250 $\mathrm{MPa}$, sedangkan pada rangka terjadi pada bagian tengah rangka, yaitu sebesar 0,860552 $\mathrm{MPa}$ dan (3) berdasarkan perhitungan teori kegagalan Tegangan Geser Maksimum (Maximum sheare stresss), tegangan yang ditimbulkan akibat beban eksternal jauh lebih kecil dari tegangan Yield-nya. Pada ketiga struktur alat pengering bawang tersebut, besarnya tegangan maksimum yang terjadi berdasarkan hasil simulasi masih jauh lebih kecil dari setengah kekuatan luluh bahan. Demikian juga berdasarkan perhitungan teori kegagalan Teori Energi Distorsi (Distortion energy), tegangan maksimum yang terjadi akibat beban eksternal juga jauh lebih kecil dari tegangan Yield-nya. Dengan demikian struktur alat pengering bawang dapat dinyatakan aman untuk digunakan pada beban kerja tersebut.

\section{PENGHARGAAN}

Ucapan terima kasih kepada bapak Zulfikar, ST. MT. dan bapak Bobby Umroh, ST. MT. yang telah membantu dan mendukung penelitian ini sehingga dapat diselesaikan dengan baik. Selain itu, kepada rekan-rekan tim riset yang telah banyak membantu dalam penyelesaian riset ini. Kepada orang tua dan saudara-saudara saya yang telah membantu dengan dukungan materil dan moril kepada peneliti, sehingga penelitian ini dapat diselesaikan dengan baik. 
Sofyan, A., Analisis Kekuatan Struktur Rangka Mesin Pengering Bawang Menggunakan

\section{REFERENSI}

Chen, S.-J., Chen, C.-Y., \& Lin, M.-R. (2018). Risk factors for crash involvement in older motorcycle riders. Accident Analysis and Prevention, 109-114.

ANSYS Mechanical APDL Structural Analisis Guide, Release 14.o. (2011). U.S.A.

Chandra, T. I. (2009). Simulasi Pembebanan Gaya Berat Pada Mill Shaft Roll Shell Di Pabrik Gula Sei Semayang Dengan Metode Elemen Hingga. Medan: Departemen Teknik Mesin Fakultas Teknik Universitas Sumatera Utara.

Hidajat, R., \& Lulus, L. (2005). Teori dan Penerapan Metode Elemen Hingga. Surakarta: UNS Press.

Kalikate, S. M., Patil, S. R., \& Sawant, S. M. (2018). Simulation-based estimation of an automotive magnetorheological brake system performance. Journal of Advanced Research, 14, 43-51.

Kohnke, P. (1999). Theory Reference Release 5.6. Canonsburg: ANSYS, Inc.

Novian, M. S., \& Rahmawati. (2015). Perancangan Sasis Mobil Harapan Dan Analisa Simulasi Pembebanan Statik Menggunakan Perangkat Lunak Ansys 14.o. Biltek Sekolah Tinggi Teknik Harapan, 4.

Shigley, J. E. (2006). Mechanical Engineering Design, Eight Edition. United States of America: The McGraw-Hill Companies.

Zulfikar. (2018). Dasar-Dasar Pemakaian Software Ansys 5.4. Medan: Program Studi Teknik Mesin Universitas Medan Area.

Zulfikar. (2018). Tutorial Analisa Beam Menggunakan ANSYS 5.4. Medan: Program Studi Teknik Mesin Universitas Medan Area.

Zulfikar, A. J., Sofyan, A., \& Siahaan, M. Y. (2018). Numerical Simulation on The Onion Dryer Frame Capacity of $5 \mathrm{~kg} /$ hour. JMEMME, 86-92. 